\title{
EFFECTS OF ERYTHROPOIETIN ON THE HEALING OF CALVARIAL BONE DEFECT
}

\author{
Maggie Ahmed Khairy ${ }^{*}$, Alshaimaa Ahmed ${ }^{* *}$, Inass Abou Elmagd ${ }^{* * *}$ and Ahmed Nabil Fahmi ${ }^{* * * *}$
}

\begin{abstract}
Objectives To evaluate the effect of a single-dose local administration versus the systemic administration of Erythropoietin on bone healing in calvarial bone defects

Material \& Methods Critical-size cranial osteotomy defects were created in 30 rabbits. The animals were randomly divided into 3 groups. The animals were randomly divided into 3 groups ( $n=10$ animals in each group). In the Group I, the bone defect was only filled with a collagen sponge soaked with erythropoietin. In the Group II, it was filled with a collagen sponge and erythropoietin injected systemically. While in the Group III, the defect was filled with a collagen sponge. The groups were further split in two for euthanasia 10- and 21-days post-surgery. New bone formation and neovascularization were evaluated by hematoxylin-eosin. For the 10-days samples, all the groups analyzed for area percent of blood vessels while on the 21- day samples, the area of new bone formation was calculated. Differences between groups were analyzed by one-way ANOVA.
\end{abstract}

Results At 10 days post-surgery, the histological analysis showed that the erythropoietin Groups exhibited a significantly higher percentage of bone formation compared with the other Group. At 21 days post-surgery, a higher percentage of new bone was observed in the erythropoietin group.

Conclusions The results suggest that both local and systemic administration of erythropoietin hormone encouraged the bone healing in critical-size calvarial defects in Rabbits.

KEYWORDS: erythropoietin, calvarial bone defect, rabbits, topical dose.

\section{INTRODUCTION}

Bone defects are considered a morbid ailment negatively affecting people's lives, they mostly occur following severe trauma, tumor resection, infection or due to congenital malformation ${ }^{(1)}$. Repair of bone defects is still a notable clinical dispute; however, bone autografts were considered for long time one of the best maneuvers to repair and aid in bone healing ${ }^{(2)}$. The fact that this procedure is associated with several drawbacks including morbidity of the donor site and limited graft quantity ${ }^{(3)}$, gave way

\footnotetext{
* Associate Professor Oral \& Maxillofacial Surgery, Faculty of Dentistry, 6th October University, Egypt

** Associate Professor Oral \& Maxillofacial Surgery, Faculty of Dentistry, Fayoum University, Egypt

*** Associate Professor Radiology, Faculty of Dentistry, Fayoum University, Egypt

**** Associate Professor Oral Pathology, Faculty of Dentistry, Bani Suif University, Egypt
} 
to myriad of researches to improve means of bone regeneration. A promising substitute to the autografts is the delivery of osteoinductive growth factors to the defect area either solitary or in conjunction with different graft types. Growth factors proved their capability to promote the formation of new bone and enhance bone healing ${ }^{(4,5)}$.

It was documented long ago that the process of bone defect repair is not only a process of regeneration of new bone, but actually an incorporation between bone formation, hematopoiesis. Equally, angiogenesis is also of paramount importance to the process to supply nutrients and excrete metabolites. Thus, it was speculated that the ideal material for bone defects repair should stimulate both osteogenesis and angiogenesis concurrently ${ }^{(6,7)}$.

The hormone Erythropoietin (EPO) has been used for treating anemia and its angiogenic effects are proven by several researches ${ }^{(8)}$. It regulates red blood cells generation in the bone marrow together with bone homeostasis ${ }^{(9)}$. EPO was proved to increase the expression of vascular endothelial growth factors (VEGFs) and bone morphogenetic protein (BMP 2) both play an essential role in vascular formation and the angiogenesis process ${ }^{(10,11)}$.

Recent studies held strong evidence that Epo receptors (EPO R) are also expressed in non-hematopoietic tissues including endothelial cells, neurons, trophoblast cells ${ }^{(12)}$. This finding directed the search for non-hematopoietic effects of EPO ${ }^{(13)}$. Despite the lack of any direct link between Erythropoietin and bone regeneration yet recent studies manifested that EPO acts directly on BMSCs to induce osteoblastic differentiation ${ }^{(14)}$. Furthermore, its ability to stimulate bone formation in vivo by targeting both hemopoietic stem cells (HSCs) and osteoblasts (15) was confirmed. These findings revealed that erythropoietin is capable to directly and indirectly regulate the formation of bone owing to its aptness of pairing its hematopoietic and bone formation capacity. Thus, Epo is presented as one of the potent bone regenerating factors.
It is worth mentioning that EPO due to its anti-apoptotic and tissue protective effects has long been used in treatment of chronic anemia ${ }^{(16)}$, myocardial infraction ${ }^{(17)}$, diabetes mellitus ${ }^{(18)}$, spinal cord injury $^{(19)}$, acute lung injury ${ }^{(20)}$. Relatively recent studies showed that EPO can increase the VEGF expression in the injury sites, promotes new vessels formation and promptly heal wounds ${ }^{(20)}$.

Recently, several studies assessed the therapeutic outcome of recombinant human erythropoietin (rh EPO) to repair bone defects and fracture, the results confirmed that EPO exhibited promising outcome concerning enhancing bone formation, cell proliferation and increasing the VEGF-mediated angiogenesis $^{(22)}$. Despite the fact that EPO stimulate osteoclast production but still the outcome of both processes is in favor to the bone regeneration ${ }^{(23)}$.

Erythropoietin maintains its therapeutic effects aside from its route of administration. EPO is usually administered systemically with several different doses and over different periods of time. Many researches adopted the concept of using high doses over a short period of time, the therapeutic outcome was encouraging regarding the rapid bone regeneration. However, the rapid healing process apparently took place only at the beginning of the regeneration process which subsequently decelerates to normal pace ${ }^{(24)}$. Nevertheless such high doses were associated with threatening conditions such as increase in hematocrit value with concomitant polycythemia. Thus, increasing the blood viscosity which can lead to blood thrombosis and stroke ${ }^{(25)}$.

Other studies supported the use of systemic low doses of Erythropoietin over a prolonged period to bypass the adverse side effects related to the high dose ${ }^{(26)}$. Results manifested that low dose, longterm EPO treatment spurts the healing process of small bone defects not only during the initial period, but throughout the healing process.

Recent researches advocated the use of a single injection of EPO and strongly endorsed its capacity to induce the desired bone regeneration over a reasonable time without any notable side effects ${ }^{(27)}$. 
Aiming to decrease the side effects associated with systemic administration of (rh EPO), many studies investigated the efficacy and drawbacks associated with its topical administration ${ }^{(28,29)}$. Recently topical therapeutic outcome of EPO in conjunction with distraction osteogenesis were inspected and the results were very promising concerning bone regeneration with no notable side effects ${ }^{(30)}$.

Obviously, studies concerning the effects of Erythropoietin local use on bone healing lack lots of evidence and verifications in terms of dosage, delivery port, side effects and adequacy as a therapeutic sole agent for bone healing versus its systemic administration.

This study was conducted to evaluate the effect of local administration versus single dose systemic administration of Erythropoietin on bone healing of calvarial bony defects of rabbits.

\section{MATERIALS \& METHODS}

\section{Animal model \& Study design}

The present study was conducted on 30 adult male New Zealand Rabbits (Oryctolagus cuniculus). Each animal was given a complete clinical, physical and radiographic examination to exclude any evidence of systemic, orthopedic or neurologic diseases. The animals included in the study were $3.5 \pm 0.2 \mathrm{~kg}$ body weight and average age $7 \pm 0.3$ months. All animals were housed and quarantined individually in separate cages in a standard day / night cycle of 12 hours. at the department of surgery, anesthesiology, and radiology, Faculty of veterinary medicine, Cairo University for one week to become acclimatized to the housing and diet.

All animal experiments and surgical procedures were conducted according to the laws of animal protection and welfare and all the study procedures were approved by the ethical committee of Faculty of Veterinary Medicine- Cairo University.
The animals were randomly divided into 3 groups $(\mathrm{n}=10$ animals in each group). All animals within the three groups performed surgical exposure of the calvarial bone under general anesthesia, a cavity defect was performed using a trephine bur. The defects in each group was treated as the following sequence. Group I, the bone defect was filled with collagen sponge soaked with erythropoietin. Group II, the defect was filled with a collagen sponge while the erythropoietin was injected subcutaneously. As for group III, the defect was filled with a collagen sponge with no additives. The groups were further split in two for euthanasia at 10- and 21-days postsurgery.

All animals were subjected to a standardized surgical protocol by the same surgeon and another operator carried out the postoperative measurements.

\section{Erythropoietin (EPO):}

Epoetin beta (Neo Recormon, Roche, Welwyn Garden City, UK) was diluted with isotonic saline $(9 \mathrm{mg} / \mathrm{mL} \mathrm{NaCl})$ to a concentration of $3,000 \mathrm{IU} /$ $\mathrm{mL}$ immediately before administration. The timing of EPO dilution is important because the company states that the concentration of polysorbate 20 contained in the drug solution is critical for the stability of EPO; if the concentration of this detergent is too low, EPO will quickly adsorb to the surfaces of the drug container and will not be available for administration. Each defect received 900 IU EPO (group I) or an equal volume of saline (group II \& III).

In group II, animals received 1 single high dose (4,900 IU per kg body weight) of EPO systemically (subcutaneously; injection site: upper back) The injection was carried on immediately after preparation of the defect.

\section{Preparation of the collagen sponge scaffold:}

In the present study we used a commercially available collagen sponges, which resorbed within 2- 4 weeks after its application (Parasorb ${ }^{\circledR}$ Cone, Resorsorba, Winsford, UK) The collagen sponges 
used were to fill the surgical bone defect and act as a carrier to the erythropoietin. A cylindrical scaffold was sectioned from the collagen sponge with a 10$\mathrm{mm}$ diameter and 5-mm in thickness. The scaffolds were either; manually socked with the erythropoietin dose and immediately placed in the defect (group I) or just soaked in saline (group II \& III).

This rational was followed that it was an easy to use application process that could be transferred to the clinical situations.

\section{Surgical procedures:}

The animals were premedicated using midazolam $(0.2 \mathrm{mg} / \mathrm{kg})$ (Pfizer Inc, New York, USA). General anesthesia was induced by intramuscular injection of ketamine $\left(10 \mathrm{mg} / \mathrm{kg}\right.$ of body weight) (Ketamax ${ }^{\circledR}$, Gujarat, India), $2 \%$ Xylazine (4 mg/kg), 0.2\% acepromazine $\left(0.15 \mathrm{mg} / \mathrm{kg}\right.$ ) (Xylaject ${ }^{\circledR}$, ADWIA Co. S.A.E., 10th of Ramadan city, Egypt) and an intravenous propofol (2 mg/kg) (Pfizer Inc,
New York, USA). Local anesthesia (mepivacaine $2 \%$ containing 1:100.000 levonordephrine) was infiltrated around the surgical site. Prophylactic enrofloxacin antibiotics were administrated via intravenous route.

The area over the operative site was prepared for aseptic surgery. The hair coat was shaved, and disinfected with povidone iodine 10\% (Betadine, Nile pharm, Egypt).

A midline incision from the frontal area to the occipital protuberance was made down to the osseous surface of the skull. A full thickness flap was raised to expose the calvarial surface on both sides of the midline. A trephine bur $(5 \mathrm{~mm})$ mounted on a hand piece at 2,000 rpm under copious saline irrigation was used to create a standardized defect. Extreme caution was applied to avoid perforation of the underlying dura mater and not to involve the sagittal suture. (Fig 1)
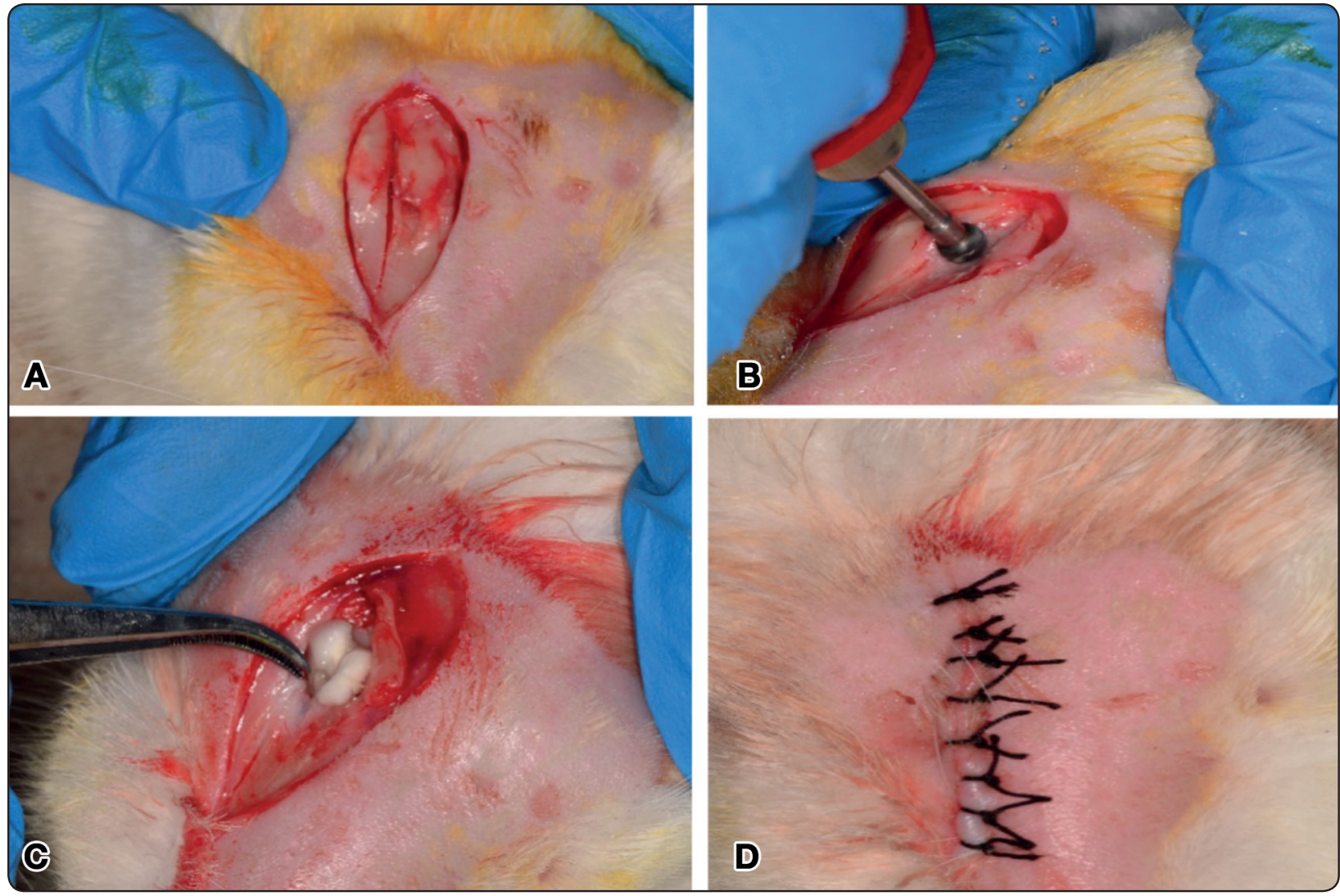

Fig. (1) Photograph showing the surgical procedures: A- Calvarial Incision, B- Bone removal, C- Application of the collagen cone in the defect, D- Closure of the wound. 
The bone defect was filled with collagen sponge socked in erythropoietin (group I) or saline (group II \& III). The animals in group II received systemic injection of erythropoietin immediately after the surgery with the dose recommended previously. (Fig 2)

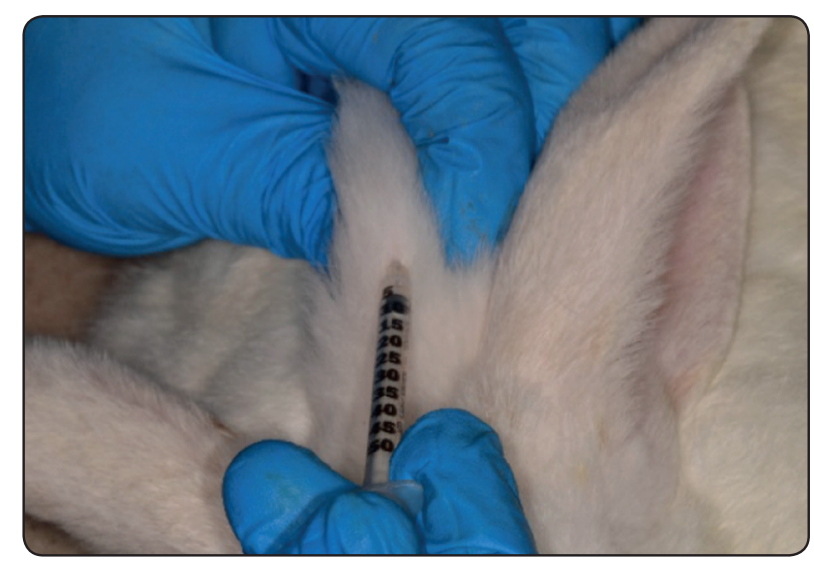

Fig. 2: Photograph showing Injection of EPO systemically (Group II)

Surgical suturing was done with standard layered suturing techniques using VICRYL 4-0 (Ethicon Johnson, Miami, FL) for deep tissues and black silk 4-0 ((Black Silk, Ethicon, Johnson \& Johnson, Somerville, NJ, USA) for the skin. The animals remained in the animal care facility and received antibiotics (benzyl penicillin benzathine $20.00 \mathrm{IU} /$ $\mathrm{kg}$ ) and anti-inflammatory medication (ketoprofen $1 \%, 1 \mathrm{~mL} / 5 \mathrm{~kg}$ ) for pain control.

\section{Animal Euthanasia:}

Animals were sacrificed at 10 and 21 days (5 animals from each group at 10 days and the rest of the animals at 21 days), using a combination of xylazine $(20 \mathrm{mg} / \mathrm{kg}$ ) and ketamine $(50 \mathrm{mg} / \mathrm{kg}$ ) administrated intramuscular followed by $25 \mathrm{mg} / \mathrm{kg}$ sodium thiopental administration in the ear vein.

\section{Radiographic analysis:}

Skulls of the rabbits were dissected, defleshed and scanned using Toshiba Asteion 4CT scanner with the following parameters: Tube voltage 120 Kvp, Milliampere 200mAs, Voxel size $0.08 \mathrm{~mm}$, scanning time 750 seconds, Gantry tilt 0.00 , focal spot size $0.5 \mathrm{~mm}$ and 14 Bit gray scale resolution.

A scout view was obtained, and adjustments were made to ensure that all samples were correctly aligned in the scanner according to the adjustment light beam before acquisition.

After acquisition, data were exported and transferred in DICOM format and downloaded via a compact Disk (CD) to personal computer for analysis, where, OnDemand 3d App software (Cybermed, South Korea) was utilized density reading.

\section{Histological analysis:}

Upon completion of the experimental periods for each group, the animals were euthanized, and the area of the original surgical defect and the surrounding tissues were removed En bloc and fixed with $10 \%$ buffered formalin for 48 hours.

The specimens were then decalcified in $10 \%$ EDTA (PH: 7.4) solution for 3 weeks. The solution changed every week. Upon complete decalcification the specimens cut transversely next to the hole and embedded in paraffin according to standard histological procedures. Five micrometer thick serial sections were cut, stained with hematoxylin and eosin stain.

The sections were observed under a light microscope (Olympus BX61, Hamburg, Germany) connected to a high-resolution digital camera (Olympus, E330, Imaging Corp), whereby digital images were obtained for each section in the twotime intervals by a single unbiased oral pathologist.

The best sections (which were given codes) were used for evaluation of area percent of formed blood vessels in the 10-days sections while osteoblastic activity, new bone formation or any inflammatory reactions were evaluated in 21-days sections for all groups. The Pathologist's observations were 
tabulated and then the codes were revealed by the authors.

Leica application suite (LAS V4 system, Switzerland) and Image $\mathbf{J}$ image analysis software were used to lock on these preselected areas for each histological section. For each of the studied groups a differential osteocyte count (normal osteocyte, abnormal osteocyte, empty lacunae) was performed for each section. The osteocytes were classified according to the morphological criteria established by Moura et al., (21) those that occupied more than $50 \%$ of their lacunae were considered normal, and those that occupied $50 \%$ or less of their lacunae were considered abnormal. Empty lacunae were also counted.

\section{Statistical analysis:}

Numerical data were explored for normality by checking the distribution of data and using tests of normality (Kolmogorov-Smirnov and ShapiroWilk tests). All data showed normal (parametric) distribution except for number of inflammatory cells data which showed non-normal (non-parametric) distribution. Data were presented as mean and standard deviation (SD) values.

For parametric data, two-way Analysis of Variance (ANOVA) was used to study the effect of group and time on different variables. Bonferroni's post-hoc test was used for pair-wise comparisons when ANOVA test is significant. For non-parametric data, Mann-Whitney U test was used to compare between the two groups as well as to compare between the two follow-up times.

The significance level was set at $\mathrm{P} \leq 0.05$. Statistical analysis was performed with IBM (IBM Corporation, NY, USA) SPSS Statistics Version 20 for Windows (SPSS, Inc., an IBM Company).

\section{RESULTS}

\section{Surgery and postoperative period:}

Surgery and anesthesia were uneventful. No signs of bleeding or unusual reactions were seen in animals during the operation. During the healing period, no deep or superficial infection were recorded. All animals showed normal food and water intake 10 days after surgery.

Upon retrieval of the bone and surrounding tissues all sites revealed undisturbed healing. There were no signs of inflammatory or foreign body reaction was visible at any time interval.

\section{Radiographic evaluation:}

Upon radiographic examination all scan showed that the average bone density values of the defect regions in each group increased over time and the differences were significant $(\mathrm{P}<0.0001)$. (Table 1)

TABLE (1) Bone density at 10 days and 21 days postoperative and the significant difference between groups using ANOVA test

\begin{tabular}{|c|c|c|c|c|c|}
\hline & Group I & Group II & Group III & $P$-value (Between & $F$ \\
\hline & Mean \pm SD & Mean \pm SD & Mean \pm SD & groups) & value \\
\hline 10 days & $27.3^{a} \pm 9.1$ & $21.5^{a} \pm 9.2$ & $14.2^{\mathrm{b}} \pm 3.1$ & $<0.001 *$ & 33.62 \\
\hline 21 days & $56.3^{\mathrm{a}} \pm 12.1$ & $49.5^{\mathrm{a}} \pm 10.3$ & $35.5^{\mathrm{b}} \pm 11.9$ & $<0.001 *$ & 94.24 \\
\hline$P$-value (Within group) & $<0.001 *$ & $<0.001 *$ & $<0.001 *$ & & \\
\hline
\end{tabular}


The greatest values of bone density were recorded in group I followed by group II with the least bone density recorded in group III. This pattern was observed at 10 and 21 days postoperative. (Table 1.)

In both observation dates, ANOVA test revealed a statistically significant difference between groups $(\mathrm{P}<0.0001)$. Tukey's post hoc test revealed a statistically significant difference between group I, II and III at 10 and 21 days while no significant difference was observed between groups I and II.

\section{Histological observation:}

Histologically, bone matrix was secreted at day 10 and increased significantly at day 21, Osteoblastic cells appeared at the early stages of 10 days and matured over time. Osteogenic activity was detected directly at the interface. A higher degree of formation of vascularized tissues, of provisional matrix, and of bone remodeling activity at 10 and 21 days was recorded in group I \& II as compared to the control group III. Meanwhile, a higher number of normal osteocytes were detected in the groups received erythropoietin.

At 10 days: Bone formation does not occur at a uniform rate across the entire defect. The initial synthesis of repair bone at ten days is woven and confined adjacent to the pre-existing lamellar cortical bone. Initially, new bone synthesis occurs peripherally restricted to areas that were close to the borders of the surgical defect. While the biggest central part of the surgical defect was occupied by connective tissue with collagen fibers parallel to the wound surface with a mild to moderate chronic inflammatory infiltrate. The complete closure of the defect was not observed at day 10 . The repair process is associated with a rich vascular front,

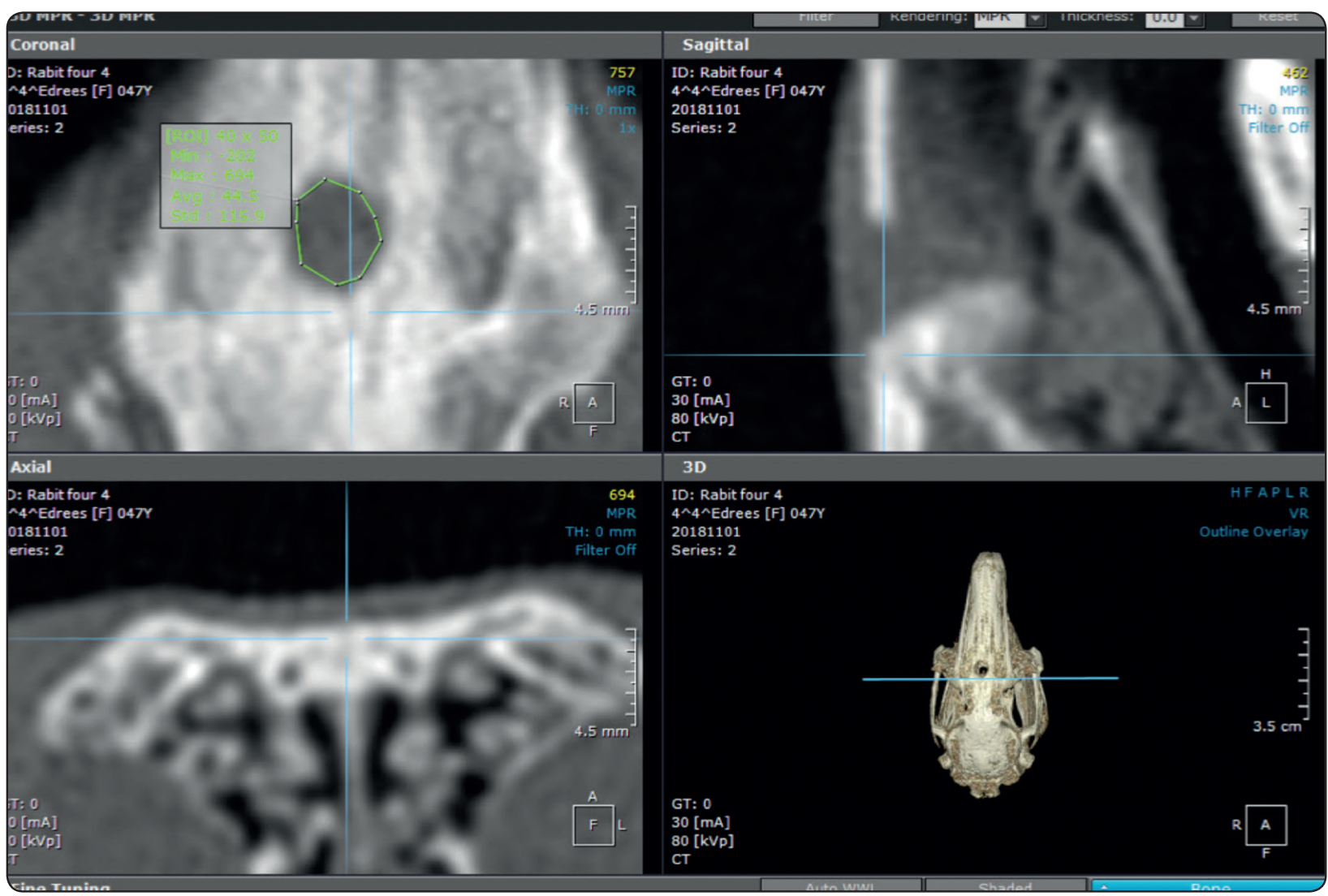

Fig. (3) Photographs showed analysis of CT scans of the bone defect 
which primarily forms from the marrow and passages into the defect at right angles to the long axis of the bone. (Fig 4)

The mean area percent of the newly formed blood vessels showed no significant difference between group I \& II while percent of the newly formed blood vessels was significantly lower in group III (Table 2)

At 21 days: All bone defects in the three groups healed with full regeneration of bone. The group I \& II showed considerable faster healing at the end of the 21 days' period together with decreased

TABLE (2) Mean area percent of newly formed blood vessel surface at 10 days postoperative and the significant difference between groups using ANOVA test

\begin{tabular}{|c|c|c|c|c|c|}
\hline & Group I & Group II & Group III & $P$-value (Between & $F$ \\
\hline & Mean \pm SD & Mean \pm SD & Mean \pm SD & groups) & value \\
\hline Area & $186544^{\mathrm{a}} \pm 192.1$ & $184206^{\mathrm{a}} \pm 197.2$ & $72059^{\mathrm{b}} \pm 93.1$ & $<0.001 *$ & 37.62 \\
\hline Area Fact & 0.06 & 0.06 & 0.02 & $<0.001 *$ & 41.3 \\
\hline Area Fill & 0.07 & 0.07 & 0.03 & $<0.001 *$ & 33.2 \\
\hline Area\% & 6.37 & 6.29 & 2.46 & $<0.001 *$ & 49.1 \\
\hline
\end{tabular}

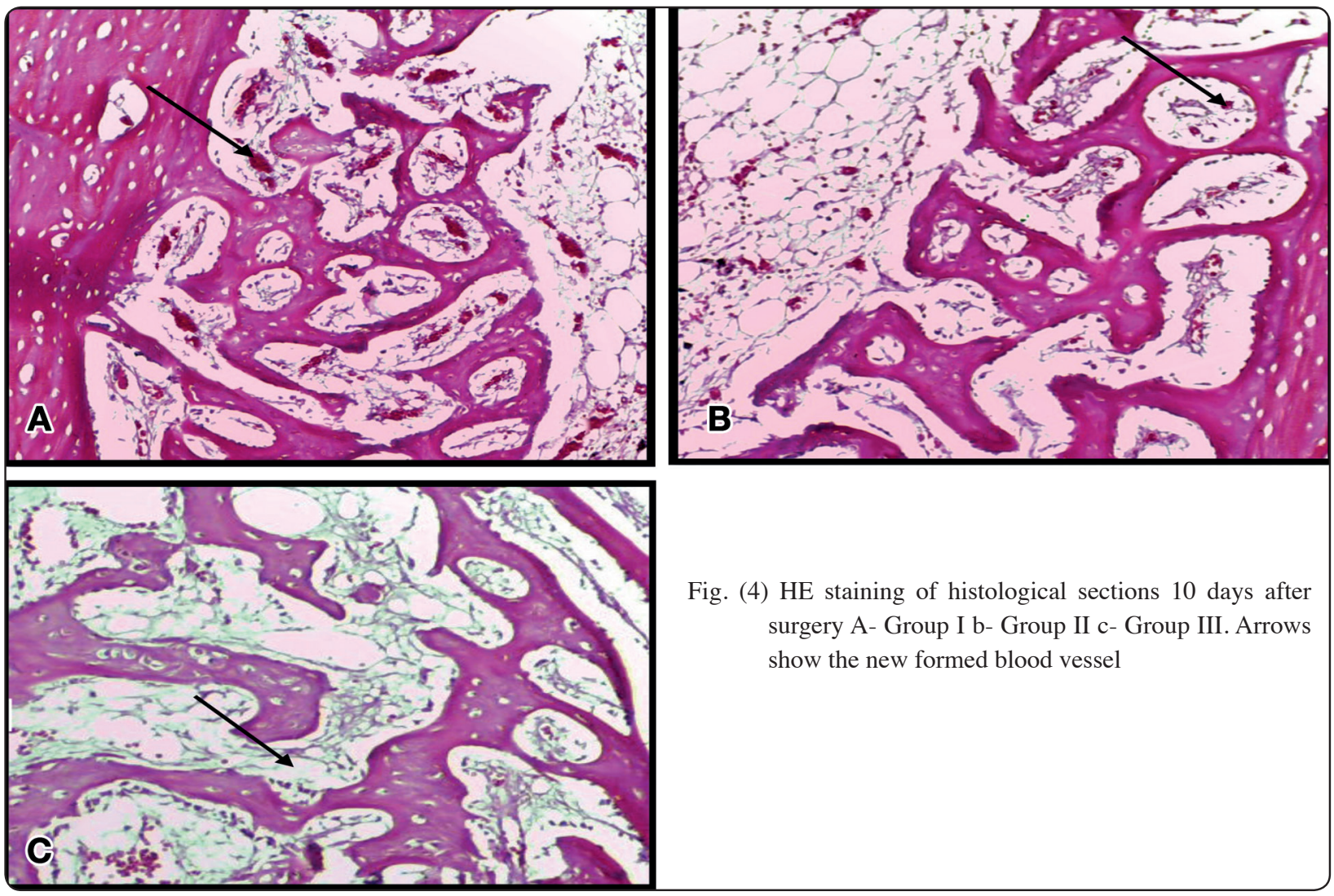


number of inflammatory cells. Bone at the periphery, which was originally woven was transformed into lamellar bone adjacent to the persisting cortices. Closer towards the center of the defect woven bone predominated and completely degraded materials.

However, in group III, the implanted materials had been mostly absorbed, but the new trabecular was sparse and only small part of the specimens showed trabecular junction. (Fig 5)

The mean percentage of normal osteocytes showed no significant difference between group I \& II while mean percent of normal osteocytes was significantly lower in group III (Table 3)

TABLE (3) Mean percentage of normal osteocytes at 21 days postoperative and the significant difference between groups using ANOVA test

\begin{tabular}{|l|c|c|c|c|c|}
\hline & Group I & Group II & Group III & \multirow{2}{*}{$\begin{array}{c}\text { P-value (Between } \\
\text { groups) }\end{array}$} & $\begin{array}{c}F \\
\text { value }\end{array}$ \\
\cline { 2 - 5 } & Mean $\pm \mathrm{SD}$ & Mean $\pm \mathrm{SD}$ & Mean $\pm \mathrm{SD}$ & $<0.001^{*}$ & 0.521 \\
\hline Mean Osteocytes & $30.1^{\mathrm{a}} \pm 3.3$ & $40.7^{\mathrm{a}} \pm 4.8$ & $23.3^{\mathrm{b}} \pm 3.1$ & $<$ \\
\hline
\end{tabular}

*significant at $p<0.05$

Tukey's post hoc test means with different superscript letters are significantly different

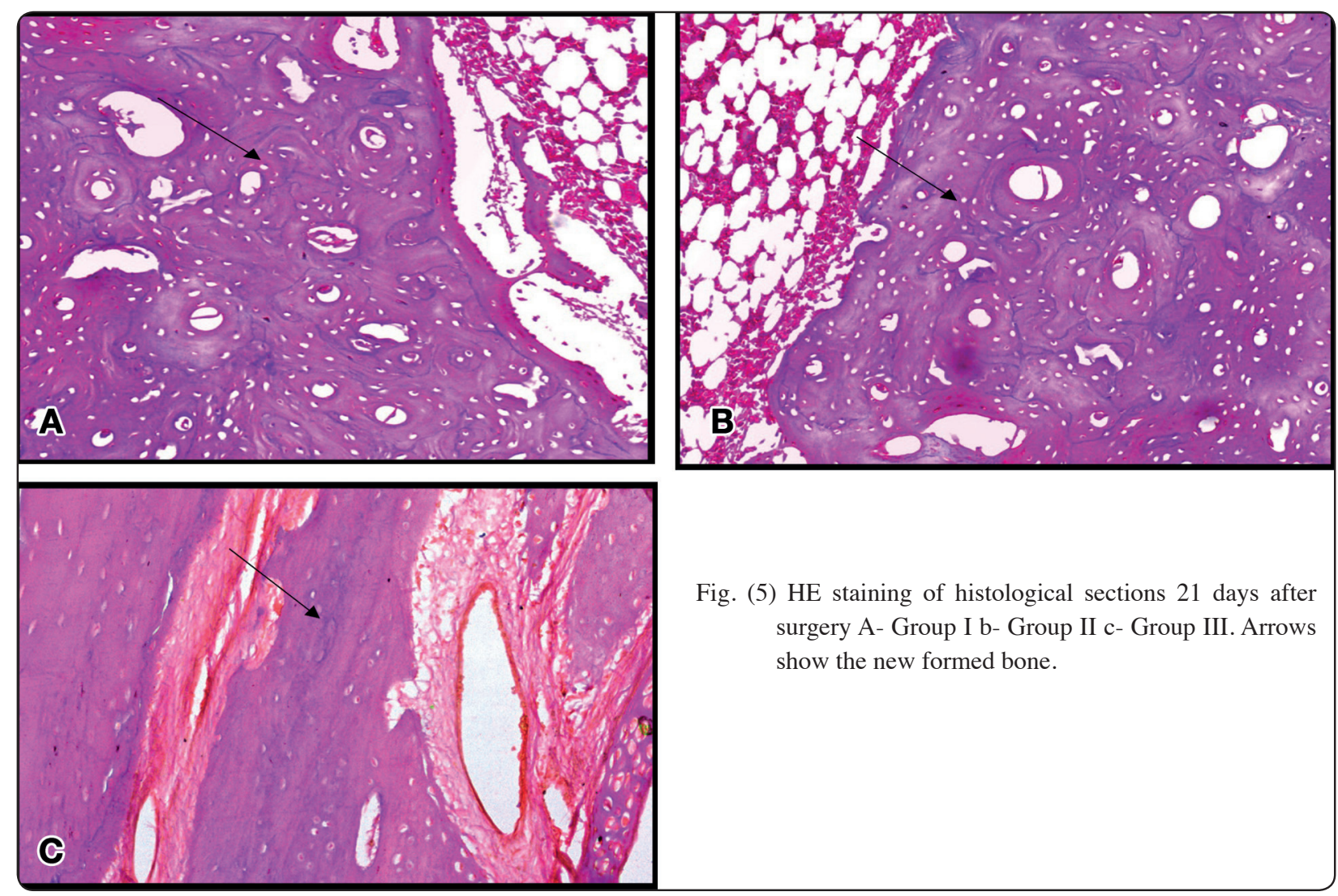




\section{DISCUSSION}

Current procedures to promote skeletal regeneration include the application of autografts, allografts, biocompatible implants, bioactive factors and mesenchymal stem cells. However, those approaches also face significant limitations due to insufficient blood supply, potential disease transmission, immunorejection, or less ability of functional engraftment. Furthermore, vascularization of 3-dimensional scaffolds for bone tissue regeneration remains a challenge. Thus, discovery of novel therapeutic approaches to improve skeletal repair and healing remains a great demand and clinical challenge in oral and maxillofacial surgery. ${ }^{(1-4)}$

Erythropoietin (EPO) is a hematopoietic growth factor that stimulates the formation of red blood cells. In recent years, the non-hematopoietic effects of EPO have been investigated. Of interest for skeletal tissue engineering, the pleiotropic capabilities of EPO include osteogenic and angiogenic potencies. (6-10)

The studies coupling the EPO to bone healing reported that the use of EPO was supraphysiologic dosage and had potential harmful implication like high blood viscosity and consecutive thromboembolic events. Many researches shifted to the use of topical administration of EPO into the bone defect to improve the efficiency of EPO on the bone formation with minimal systemic effect. $(11,14,15,23,27,29)$

The aim of the present study was to evaluate the effect of a single-dose local administration versus the systemic administration of Erythropoietin on bone healing in calvarial bone defects.

In the present study, animals in group II were injected systemically with a single dose of erythropoietin to avoid the risk of side effects reported in other studies. Moreover, single erythropoietin dosing facilitates clinical application and proved to be sufficient to improve the bone healing. ${ }^{25,27,31)}$

The histological outcomes showed that group II which received EPO as a systemic single dose were more effective on repairing the bone defects and can promote the osteogenesis and angiogenesis especially in the early stage of bone healing when compared with group III that did not received any EPO hormone.

This was in accordance with Previous studies that reported EPO could promote proliferation and induce to osteoblast, accelerate the growth of osteoblast and strengthen its osteogenesis function. $(24,26,27,30,31)$

Furthermore, Omlor et al (27), who use the single systemic EPO dose to promote bone healing in rabbits concluded that Initial single dosing with EPO was enough to increase bone healing substantially after 12 weeks of follow-up. They reported that the single application of EPO at early time point appears to be most effective and intraoperative administration as a single dose appears most attractive to improve the bone healing.

The group that received topical dose of EPO also showed a more new formed vessels in the sections at different time and the defect repairing effects showed improvement when compared to control group. This indicates that the topical application of EPO exerted a significant function of osteogenesis and angiogenesis.

Similar results within the histological evaluation with Li et al ${ }^{(32)}$, they used EPO on DBB scaffolds to evaluate the healing of the bone defects. they concluded that PO has significant effects on bone formation and angiogenesis and has capacity to promote the repair of bone defects. They stated that release of EPO was in a relative stable dose for more than 10 days and accumulative dose had not influenced the body systems.

Moreover, Rölfing et al ${ }^{(29)}$, who filled the bone 
defect with EPO on autograft, a collagen carrier, or a polycaprolactone (PCL) scaffold concluded that topical administration of EPO on a collagen carrier moderately increased bone healing. The dosing regime was safe and could have possible application in the clinical setting.

On the other hand, Omlor et al ${ }^{(27)}$, who used absorbable gelatin sponge was EPO as local treatment group to fill into the bone gap reported that the local application to surgically open defect carries a high risk of loss of EPO during application compared to the subcutaneous needle in tissue that has not been surgically open and EPO transported more quickly after local application in bone defect with high initial peak of serum concentration but shorter elimination half-life.

The present research provides initial promising results regarding the use of EPO to accelerate bone healing. However, there was limitations that need to be addressed in future studies. The limitations include the number of the animal model on each group and systemic effect of the EPO in both local and topical applications.

Further studies will be needed to evaluate the long-term outcomes in the bone healing and more studies should be directed toward the safety and tolerability of the drug in the animal models.

\section{CONCLUSION}

Topical application of erythropoietin has a significant effect on bone formation and angiogenesis and has capacity to promote repair of the bone defect.

\section{Conflict of interest}

The authors declare that they have no conflict of interests.

\section{Source of funding}

The study was self-funded by the authors.

\section{REFERENCES}

1. Roddy E, DeBaun MR, Daoud-Gray A, Yang YP, Gardner MJ. Treatment of critical-sized bone defects: clinical and tissue engineering perspectives. Eur J Orthop Surg Traumatol. 2018;28:351-362

2. Pape HC, Evans A, Kobbe P. Autologous bone graft: properties and techniques. J Orthop Trauma. 2010;24: S36-40.

3. Kao ST, Scott DD. A review of bone substitute. Oral Maxillofac Surg Clin North Am. 2007; 19:513-21

4. Choi BH, Im CJ, Huh JY, Suh JJ, Lee SH.Effect of plateletrich plasma on bone regeneration in autogenous bone graft. Int J Oral Maxillofac Surg. 2004; 33:56-9.

5. Cakir S, Gultekin BA, Karabagli M, Yilmaz TE, Cakir E, et al. Histological Evaluation of the Effects of Growth Factors in a Fibrin Network on BoneRegeneration. J Craniofac Surg. 2019; 30:1078-1084

6. Geiger F, Bertram H, Berger I, Lorenz H, Wall O, Eckhardt C, Simank H G, Richter W. Vascular endothelial growth factor gene-activated matrix (VEGF165-GAM) enhances osteogenesis and angiogenesis in large segmental bone defects. J Bone Miner Res 2005; 20: 2028-35.

7. Kai Hu Bjorn, R Olsen. The roles of vascular endothelial growth factor in bone repair and regeneration. Bone 2016;91: 30-38.

8. Eschbach JW ${ }^{1}$, Kelly MR, Haley NR, Abels RI, Adamson JW. Treatment of the anemia of progressive renal failure with recombinant human erythropoietin. N Engl J Med. 1989 20; 321:158-63.

9. Eggold JT, Rankin EB. Erythropoiesis, EPO, macrophages, and bone. Bone. 2019;119:36-41

10. Kimáková P, Solár P, Solárová Z, Komel R, Debeljak N. Erythropoietin and Its Angiogenic Activity. Int J Mol Sci. $2017 ; 18: 1519$.

11. McGee SJ ${ }^{1}$, Havens AM, Shiozawa Y, Jung Y, Taichman RS. Effects of erythropoietin on the bone microenvironment. Growth Factors. 2012;30:22-8.

12. Juul SE, Yachnis AT, Christensen RD. Tissue distribution of erythropoietin and erythropoietin receptor in the developing human fetus. Early Hum Dev. 1998; 52:235-49.

13. Murat O. Arcasoy. The non-haematopoietic biological effects of erythropoietin. British Journal of Haematology. 2008; 141:14-31. 
14. Guo L, Luo T, Fang Y, Yang L, Wang L, Liu J, Shi B. Effects of erythropoietin on osteoblast proliferation and function. Clin Exp Med. 2014; 14:69-76.

15. Shiozawa Y, Jung Y, Ziegler AM, Pedersen EA, Wang J, Wang Z, Song J, Wang J, Lee CH, Sud S, Pienta KJ, Krebsbach PH, Taichman RS. Erythropoietin couples hematopoiesis with bone formation. PLoS ONE 2010;5: e10853

16. Tong EM, Nissenson AR Erythropoietin and anemia. Semin Nephrol. 2001; 21:190-20

17. Steppich B, Groha P, Ibrahim T, Schunkert H, Laugwitz KL, Martin Hadamitzky M, Kastrati A, Ott I. Effect of Erythropoietin in patients with acute myocardial infarction: five-year results of the REVIVAL-3 trial. BMC Cardiovasc Disord. 2017;17:38

18. Maiese K. Erythropoietin and diabetes mellitus. World J Diabetes. 2015; 6: 1259-1273

19. Georgios K, Theodossios A. Birbilis. Erythropoietin in spinal cord injury Eur Spine J. 2009 ; 18: 314-323.

20. Ozer EA, Kumral A, Ozer E, Yilmaz O, Duman N, Ozkal S, Koroglu T, Ozkan H. Effects of erythropoietin on hyperoxic lung injury in neonatal rats. Pediatr Res. 2005; $58: 38-41$.

21. Moura CG, Betoni WJ and Dechichi P. Cienc Odontol Bras Histomorphometric analysis of bone graft storage in physiologic solution [in Portuguese].. 2005; 8:23-27.

22. Holstein JH, Menger MD, Scheuer C, Meier C, Culemann U, Wirbel RJ, Garcia P, Pohlemann T. Erythropoietin(EPO): EPO-receptor signaling improves early endochondral ossification and mechanical strength in fracture healing. Life Sci. 2007;80:893-900.

23. Hiram-Bab S, Liron T, Deshet-Unger N, Mittelman M, Gassmann M, Rauner M, Franke K, Wielockx B, Neumann D, Gabet Y. Erythropoietin directly stimulates osteoclast precursors and induces bone loss. FASEB J 2015; 29: 1890-900.
24. Bozlar M, Kalaci A, Aslan B, Effects of erythropoietin on fracture healing in rats. Saudi Med J 2006 27:1267-1269

25. Lippi G, Franchini M, Favaloro EJ. 2010. Thrombotic complications of erythropoiesis-stimulating agents. Semin Thromb Hemost 36:537-549.

26. Garcia P, Speidel V, Scheuer C, Laschke MW, Holstein JH, Histing T, Pohlemann T, Menger MD. Low dose erythropoietin stimulates bone healing in mice. Journal of orthopaedic research: official publication of the Orthopaedic Research Society. 2011; 2:165-172.

27. Omlor GW, Kleinschmidt K, Gantz S, Speicher A, Guehring T, Richter W Increased bone formation in a rabbit long-bone defect model after single local and single systemic application of erythropoietin. Acta Orthopaedica 2016; 87: 425-431.

28. Nazeman P, Rad MR, Khojasteh A. Topical erythropoietin as a novel preventive and therapeutic agent in bisphosphonate-related osteonecrosis of the jaw. Dent Hypothesis 2016; 7:56-60

29. Rölfing JH, Jensen J, Jensen JN, Greve AS, Lysdahl H, Chen M, Rejnmark L, Bünger C. A single topical dose of erythropoietin applied on a collagen carrier enhances calvarial bone healing in pigs. Acta Orthopaedica 2014; 85: 201-209.

30. Mihmanli A, Dolanmaz D, Avunduk MC, Erdemli E. Effects of recombinant human erythropoietin on mandibular distraction osteogenesis. J Oral Maxillofac Surg. 2009; 67:2337-43.

31. Rölfing JH. The effect of erythropoietin on bone. Acta Orthop Suppl. 2014; 85:1-27.

32. Li D, Deng L, Xie X, Yang Z, Kang P. Evaluation of the osteogenesis and angiogenesis effects of erythropoietin and the efficacy of deproteinized bovine bone/recombinant human erytropoietin scaffold on bone defect repair. J Mater Sci Mater Med. 2016; 27:101. 